\section{FRACTURES OF THE FACIAL SKELETON}

By N. L. Rowe, F.D.S. R.C.S., L.R.C.P., M.R.C.S., L.M.S.S.A., H.D.D. R.C.S., and H. C. KILLEY, F.D.S. R.C.S., L.R.C.P., M.R.C.S., L.M.S.S.A., H.D.D. Ed. Pp. xxxvi +923, with I23I illustrations, I4 in colour. Edinburgh: E. \& S. Livingstone Ltd. 1955. £6.

The authors of this excellent book have set out to produce a comprehensive work of reference embracing the entire subject of maxillo-facial injuries in all its aspects. The resulting volume is a superb production, beautifully produced and illustrated. The authors' immense experience in their field and reasoned and practical approach to their problems leaves little or nothing to criticize in the subject-matter or its method of presentation. One wishes, however, that it might have been possible to condense the work somewhat in the interest of producing a rather more portable volume and one rather less expensive. In view of the authors' declared intention it would be foolish to suggest omitting any of the surgical or pathological material, but some of the illustrations, while uniformly excellently reproduced, are perhaps not particularly instructive. One also wonders whether any radiologist, anaesthetist or medical historians are likely to refer to this work, and the surgeon should not be very closely concerned with the technical aspects of these specialties, vitally important though they are in the teamwork necessary for maxillo-facial work.

Inevitably much of the material relates to war injuries, but the lessons learned from them are very applicable to the generally different industrial and road accidents with which the majority of faciomaxillary surgeons are no doubt occupied today, and Rowe and Killey give most useful guidance to the junior surgeon inexperienced in this type of case who is required to institute life-saving measures and render the cases fit for transport to maxillofacial centres. For this reason, among others, one hopes that this splendid work will be available to as many such surgeons as possible, and any mild criticisms one has ventured to make are merely because the cost of the book might deter some from purchasing it personally, admirable value though it undoubtedly is.

\section{POLIOMYELITIS}

By W. Ritchie Russell, C.B.E., M.D., D.Sc., F.R.C.P. Second Edition. Pp. xi + 147, with 40 illustrations. London: Edward Arnold Ltd. r956. I6s.

Poliomyelitis is the subject of considerable discussion at the present time and there is no doubt that this book is a most important contribution to its literature. It gives a comprehensive review of he opinions of those working in the Department of Neurology at Oxford as well as the results of their researches and experiences, particularly in the treatment of this disease.

The clinical features are first described followe by sections on the physical examination and differential diagnosis. There is then a chapter of the factors influencing cell vulnerability, the mosł: important of which undoubtedly appears to $b \&$ physical activity after the onset of the major illnes? However, the most interesting and informative parts of the book are the chapters on the treatmerse of patients stricken by the severer forms of infantile paralysis. There must be few illnesses where medical management and skilled nursing so oftefp play the deciding role in the final outcome. This is particularly so in cases of bulbar poliomyelitis and in those suffering from respiratory paralysis, It is perhaps not widely enough realized thaff although the various methods of artificial respiration now available may undoubtedly be life-saving, the in their turn if improperly used may endanger thes patient's life. Anyone wishing further information on this aspect of the subject will find in this boog much that is of practical importance; the advice on treatment being clearly and concisely presented. $\infty$

Since the last edition a great deal of work has been done on the various methods of helping patients with respiratory insufficiency, especially by intermittent positive pressure respiration, and thissection of the book has been rewritten and brougl up to date.

The book can be highly recommended to Oath $_{4}$ those interested in the subject and who, $R$ limited experience, may be called upon at stof notice to treat seriously ill patients suffering frore the graver complications of poliomyelitis.

N.S.G.

\section{A SHORT PRACTICE OF SURGERY}

By Hamilton Bailey, F.R.C.S., F.A.C.S F.I.C.S., F.R.S.E., and R. J. MeNeILl LovE. M.S., F.R.C.S., F.A.C.S., F.I.C.S. Tent最 edition. Pp. viii + I I26, with I4I I illustrations? $27 \mathrm{I}$ in colour. London: H. K. Lewis \& Co. Ltd 1956. £4 4s.

This tenth edition of 'Bailey and Love' shows one notable change from its predecessors. New authors have been introduced to write upon subjects on which they are recognized authorities. M\$ William Cleland has contributed two excellen chapters on the thorax, heart and pericardium, an Mr. John Charnley and Mr. Geoffrey Knight have been responsible for greatly improving the sections on orthopaedics and the nervous system. The original authors have thoroughly revised the re mainder of the text and brought it up to date with recent advances in surgery and therapeutics.

Minor points here and there can be selected form critical comment as not in keeping with current practice. For example, the authors still recomv mend gastro-jejunostomy for most cases of chronie 